\title{
LA ESCRITURA EN LOS TRATADOS DE BALTASAR GRACIÁN
}

\author{
Aurora Egido \\ Universidad de \%aragoza
}

Si los resortes de la voz ocupan amplio espacio en los tratados de Gracián, también la letra recibe en ellos atención constante hasta constituir una auténtica poética de la escritura cuyos mayores alcances se logran en la Agudeza y, sobre todo, en Eil Criticón.

El Héroe ya muestra en su dedicatoria autógrafa a Felipe IV una concepción clásica del libro, tal y como los prólogos latinos la presentaban, minimizándolo para así encarecer mejor el papel del destinatario:

Este juguete de grandezas, este melindre de discreción, llega a los reales pies de V.

M. a blasonar lauro en las dos plantas, corona cada una de un mundo'.

I a retórica de la humildad convierte la dedicatoria a Lastanosa de 1637 en un ejercicio físico, como de quien, escribiendo, aprende a dar los primeros pasos o "primer pino del discurso», y convierte el libro en "aprendiz de hombre que se arriesga a unos brazos abiertos». Ilumanización tipificada por Marcial y otros predecesores, repeticla con creces en los preliminares librescos del Siglo de Oro cspañol.

Los cuidados que Gracián puso en la escritura de lil Héroe, antes de (larlo a la imprenla, quedan bien patentes en su esmerado estilo. Pulcritud y claridad de letra que se compagi-

1.- Salvo indicación contraria, seguiré para las citas la edición de Miguel Batllori y Ceferino Peralta, Baltasar Gracián, Obras completas I, Madrid, Atlas, 1969. Véase p. 241. En el prólogo de lastanosa a I:I Discreto se alude a cque el rey Felipe IV, al leer F.I Héroe, dijo: «es muy donoso este brinquiño) (Ib., p. 311$)$. 


\section{AURORA IEGIIDO}

nan con los realces de la precisión, la agudeza, el equilibrio y la variedad. La fisicidad de la escritura tiene en esta obra un buen correlato con la gue la lengua presenta en toda la obra (lel jesuita? ${ }^{2}$. Voz y letra alcanzan en él rango y visajes humanos, convirtićndose su autor en un aprendiz de ingenio, sujeto a las lecciones y correcciones del mecenas oscense, cn cuyo camerín libresco El Iléroc apenas aspira a merecer un discreto rincón. La biblioteca lastanosina aparece concebida como un cosmos en el que el libro dedicado tan sólo es, en la alacena, un signo más de la agudeza allí (lepositada por su dueño.

La idea del libro como pecueño mundes que reduce al hombre, que es hombre o microhombre, late en la de(licatoria al lector de este tratado; "libro enano» que pretende conformal "un varón gigante» y, multum in parvmm, sacar en breves periodos un varón máximo. La lella se convicrte así en traslación de vida, pero también en síntesis de otros libros, "espejo manual de cristales ajenos y yerros míos».

El héroe es, de cste modo, libro que empieza niño y que se desarrolla en veinte primores, siendo el final "primor último y corona». Pasos vitales y mnemotécnicos que se ajustan a la eclad épica y que juegan con la mano de oro ciceroniana en sus consabidos múltiplos ${ }^{3}$.

Ia metáfora gráfica de la cifra que plagará las páginas del Criricón está ya en cl primor segundo, "Cifiar la voluntad», de lil lléroe, donde el arte dicta como macstro los términos del discurso ético, con el fin de (jue el varón excelente solape sus pasiones y nadic «acierte a descifrar su voluntad» (p. 246) ${ }^{4}$. La eminencia en lo mejor conlleva los realces de la pluma (p. 252) y se conforma como un compuesto alegórico: cabera de filósofo, lengua de orador, pecho de atleta y «texto conque en favor del corazón arman, algunos, pleitos a la inteligencia» (p. 248).

Pero si en El lléroe no faltan los destellos del grafismo ambivalente (al despejo, "por

2.- Miguel Romera-Navarro, Essudio del amtógrafo de "El Héroe" graciano (orrografia, comrecioness" estilo), Madrid, RFi:, 1946, ha estudiado el largo millar de correcciones y enmiendas de mano de (iracián que presenta este interesante manuscrito de la Biblioteca Nacional. Scgún él, Ciracián se esmeró èn la letra, que tenía muy moderna, mucho más que otros escritores de su tiempo, como Cervantes, Lope y Calderón. También cuidó más que cllos los usos del punto final. Véanse pp. 11, 23, 71 y 195 ss., para estas cuestiones y el estilo. Sobre los problemas de puntuación, consúltese el curioso artículo de José Manuel Blecua, "Nolas sobre la puntuación española hasta el Renacimiento», Homenaje a Julián Marías, Madrid, Espasa-Calpe, 1984, pp. 121-130. Para la dedicatoria a Lastanosa, Obras completas, ed. cit., pp. 241-2. I.os aspectos de la oralidard en (iracián han sido tratados en mi trabajo «De I.a l.cngua de Erasmo al cstilo de (jracián». II Curso sobre Lengua y Literamara ('n Aragón (Siglos de ()ro), ed. de Aurora ligiclo y' 'Tomás Buesa, \%aragoza, Instilución Fernanslo el Católico, 1992, pp. 141-66.

3.- Para los aspectos mnemolécnicos y Gracián, mi arlículo "El arte de la memoria y l:l Criticón», Gracián y su época, \%aragora, Institución Fcrnando el Católico, 1986, pp. 25-66, y Fernando Rodriguez de

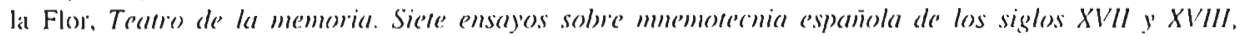
Salamanca, Junta de Castilla y León, 1988. Para el libro como speculum y mundo abreviado, Einst R. Curtius, Literanura Européa y' Edad Media Latina. México, FCI:, 1955, pp. 472-3. Gracián, que hablat constantemente de los partos de la lengua, recoge también la idea del libro como parto del ingenio. Sobre la mano de oro, Fernando R. de la flor, "La mano momónica", Fragmentos, 17-8-19, 1991, pp. 17 2.5 .

4.- En el primor III volverá a usar el lérmino: «La valentía, la prontitud, la sutileza de ingenio, sol es deste mundo en cifra; si no rayo, vislumbre de divinidad» (p. 247). "Cifrar la voluntad» es el epígrafe del segundo capítulo o) "primor». 'También ahí juega con las palabras ojos-hojas (p. 247), como cn El Criticón. (Otros ejemplos pueden acarrearse: «cifra de la riqueza, pasmo de explendor» es el corazón de rey, en el IV, p. 248. Y en el VI, emplea «cifrar todla una caltegoría», p. 251. 


\section{L.A I:SCIRITURA FN I.OS TRATADOS LEE BALTASAR GIRACIÁN}

robador del gusto, le llamaron garabato»), li/ Polínico agranda sus márgenes desde la traza de Fernando el Calólico, «breve diseño de sus heroicas acciones» (p. 27.5), según lo califica en la censura Andrés de Uztarroz. I a dedicatoria al Ducpue de Nochera alienta una pluma sin «el favonio de la lisonja», pero que envidia la calidad y elegancias de las de Tácito y Comines. Fl rey parece haber dejado en la caligrafía de sus aulógrafos "deformes caracteres, pero informaclos de mucho espíritu». I.o arcano de sus inscripciones va así en correlato con la profundidad de su pensamicnto (p. 276).

No insistiré en los alcances de una obra medida y preparada sobre los blancos de la página impresa en estudiacla composición y (lisposición, así como en las claves gue cl propio Gracián da para desvelar al lector la autoría de El Políricos. El archivo de la fama y los catálogos del aplauso etcrnizan a los reyes, pero también su propia incursión en las letras, "haciendo blasón de la pluma y de la espacla»". Estilo, conteniclo y formato se alían, en diclado único ante el lector, en éste como en los demás tratados del jesuita.

La brevedad de F/ Discreto resalta en lá misma dedicatoria al príncipe Baltasar Carlos: «pequeño es el don»? Iil perlil del hombre de plausibles noticias es hombre de estudio y libros que se alimenta de la erudición, delicioso banquete de los entendidos*. El libro se ocupa de valores unidos a los de la palabra y la actitud, sin extenderse demasiado en el encomio de la escritura. No obstante, aparece en él la consigna temprana de la cifira (p. 327), que tanta importancia tendria en E/ Criticón, avalando la variedad universal. Tampoco faltan otras referencias como la de la lectura del semblante del buen entendedor; "puerta del alma, sobrescrito del corazón» (p. 328).

Gracián, al igual que Shakespeare en Romeo y Julieta y en otros textos, enseña a leer en el libro del rostro, y cifra la talla del varón perfecto en la uestudiosidad y contino trato con los sabios, ya muertos, en sus libros, ya vivos, en su conversación»". Fil elogio de Lastanosa

5.- VÉase a este propósito mi introducción a la ed. facsímil de El Políico don Fernando "al Conólico. Yaragoza, Institución Fernando el Católico, 1985, donde señalo los aspectos tipográficos de la princép)s y sus consecuencias estilísticas. Fl nombre del rey «lBaltasar» es oráculo de sí mismo y enunciado del de el autor (p. 279). Fi de "Graciano» "religiosísimo» lo completa posteriormente (p. 284). Fi acróstico de Baltasar (jacián desveló a su autor en los preliminares de El Discrete) (p. 31.3), como se sabe.

6.- Pp. 289-290 y vide pp. 301-2. El propio rey Cátólico entró en el catálogo de la fama allayendo a valrones ilustres en Ietras humanas y divinas. Fi libro mismo se convicrte en retrato, o mejor dicho, en "ruda copia del monarca" (pp. 3()()-2). En la citada introducción (supra, nota 5), hice notar cómo la caja tipográfica de El Héroe fue respetadat en los tratados posteriores, salvo en el Arte de ingernio, Madrid, 1642, en Agudeza y arle de ingenio, Huesca, 1648 y en lil Crinicón, de formato mayor.

7.- Este prólogo muestra la misma reticencia a publicar que la que Pedro Manucl de Unea mostrara con su (incionero, al temer la divulgación incontrolada de su obra. Dice el jesuita: "que materias tan sublimes dignas de solos héroes, se vulgaricen con la estampa, y que cualquier plebeyo, por precio de un real, haya de malograr lo que no le tiene». I a división quíntuple, en venticinco apartados, cinco más que los de l:I lléroe, divide tipográficamente la obra, siguiendo los esquenas mnemotécnicos de la mano de oro (jue aparecen también en otras obras de Gracián.

8.- Pp. 324-5. I a erudición ocupa largo espacio en esta obra, como en el elogio de ta casa-museo de Lastanosa.

9.- P. 349. Véanse las observaciones sobre la fisicidad de las palabras y su reflexión en el diálogo entre U\%tarro\% y el autor, donde el contenido aparece en la forma misma. La defensa de la variedacl vuelve en sus reflexiones sobre el humor en la novela, tema que trata con mesura, procurando gue no se convierta en farsa (p. 331). El vocabulario académico ronda, a cambio, la observación de lono humorístico, al hablar de quienes no saben conocerse (p. 343). I a cultura es marca del aliño que dele reinar en la obra y 
y del tolosino filhol conlleval el de sus famosas bibliotecas, jardines de flores y elocuencia, espacios de cultura en íntima relación con la lalla de sus clueños ( $p .351)^{\prime \prime}$. Fextremos que reaparecerán años despućs en la peregrinación alegórica de Andrenio y Critilo.

F.l discreto se conforma con pespuntes de erudición y pasto de libros que le permiten alcanzar la talla del hombre juicioso y mesurado. Acpuí precisamente se adelanta el juego cjue tendrá el Descifrador en El Criticón al delinear a los discrelos como ugrandes descifradores de intenciones y (le fines: que Ilevan sienere consigo la curiosa contracifra» (p. 352). El texto insiste en los poderes de la lengua y describe las partes de la vida de un discreto como una jornada en tres actos. Enigma que él mismo desvela bajo metáforas de lectura y vida, como un viaje en tres estaciones: «la primera en hablar con los mucros, la segunda con los vivos, la tercera consigo mismo» (p. 363). Programa de vida y obra que repetirá al pie de la letra en El Criticón.

La existencia del discreto se corona, tras un repaso a todas las artes y ciencias, en un doble aprendizaje universal. lanto libresco como moral. Toda la vida se hace un discurrir sobre los libros y las artes, a la par (que un peregrinar y ver el mundo (p. 36.5). Camino que adelanta, como se ve, la tesis de su famosa alegoría, en esa andadura con los pies y con la vista, a la par que con la inteligencia. La instancia de percibir y de leer se concibe, en la aduana y registro del entendimiento, como un acto corpóreo de deglución y alimentación anímica, muy del gusto de La lengua de Frasmo de Rotterdam:

Traga primero leycndo, devora viendo, rumia después meditando, desmenuza los objectos, desentraña las cosas averiguando las verdades, y aliméntase el espíritu de la verdadera sabiduría (p. 36.5).

Los trescientos aforismos del Oráculo mamual y arte de prudencia se configuran como síntesis tipográfica del contenido de todos sus tratados. Ya el título apela a la materialidad de un libro que, como dice la aprobación, abriga «en tan poco cuerpo tanta alma», siendo quintalesencia del arte que predica y "cifra» de todos los demás libros de su autor (p. 368)". La metáfora gráfica que, como hemos visto, engalana los tratados anteriores, va acompañada de otrats de índole gramatical y gastronómica, en esa doble imagen, corporal y libresca, que ticne cocla la obra del jesuita'?

Gracián, como Estacio o Marcial, elogia la obra pequeña, el libro mínimo que todos sus tratados corroboran, y hasta ironiza sobre el carro largo de los libros que son estimados «por la corpulencia, como si se escribicsen para cjercitar antes los brazos cjuc los ingenios» (p. 38(0). Presupuesto (que, sin embargo, rompería años después en su obra máxima, como es obvio. Otros tópicos (lestila el Oráculo, como el tan extendido de que no hay libro que no con-

en la vida (p. 349 ss.). Véase mi artículo «La variedad en la Agudeza de Baltasar (iracián», frromteras de la poesía e'n el Barroco, Barcelona, E(litorial Críticia, 1990, pp. 241-258.

10.- Más adelante, al detallar el curiculum del sabio discreto y sus lecturas, le hará pasear por jardines de poesía y otras lecturas variadas (p. 36.3.).

11.- La (ledicatoria a Don Luis Méndez de Ilaro, pero que parece declicatoria graciana, insiste cn la imagen: "Cifra tedo un varón de prenclas, y descifra de las que en V.E. veneró" (p. 374). Es oráculo sentencioso y preciso del vivir, microcosmos de «todos los doce Gracianes».

12.- «Usar, no abusar de los reflejos» (p. 384), «sirva éste de memorial a la razón en el banquete de sus sabios, en que registre los platos prudenciales que se le irán sirviendo en las demás obras, para distribuir el gusto genialmente" (p. 374). 


\section{LA ESCRITURA EN LOS TRATADOS DE BALTASAR GRACIÁN}

tenga algo bucno (p. 404), aunque en él lo que se pretenda cs justamente que lo contenga todo.

El jesuita insiste en los alcances del juicioso como «gran descifrador» (p. 385), adelantándose a las capacidades de zahorí que Critilo y Andrenio necesitarán para avanzar por el mundo y por la vida sin engañarse. Pero como allí, el Arte de prudencia no se para sólo en lo estético, sino que apura al máximo las imágenes y los referentes tipográficos. Hombres y libros son todo uno, que «tanto es menester tener estudiados los sujetos, como los libros» (p. 408). Toda advertencia es poca, según él, así en la escritura como en la vida (p. 406). Sin que falte al concurso la referencia al libro verde, a propósito de la fama (p. 401). Acordar palabras con obras es empeño constante del Oráculo como de toda la obra graciana ${ }^{13}$. La retórica, la escuela, la pluma, los pinceles sirven de metáfora vital y literaria, aunque el autor termine por preferir «saber un poco más y vivir un poco menos» ${ }^{4}$. Las jornadas vitales de Andrenio y Critilo parecen contenerse ya en los citados actos de la comedia humana a los que el Oráculo vuelve en sus aforismos últimos:

Gástese la primera estancia del bello vivir, en hablar con los muertos; nacemos para saber y sabernos, y los libros con fidelidad nos hacen personas (p. 425).

Leer como vivir, vivir para leer y viccversa parecen ser lemas constantes, aunque Gracián, en los aforismos de ésta y otras obras, intente que el camino de una y otra acción sea tan cauteloso como reflexivo. Prudencia en el descifrar para ver detrás de todo lo aparente.

Todo cuanto de metáfora escrituraria desvelan los tratados profanos aparece en su opúsculo religioso. El Comulgatorio, al igual que «sus hermanos» El Héroe, El Discreto, El Político y el Oráculo, fue concebido como "pequeño libro», engrandecido por el destinatario una vez más; en este caso, la camarera de la Rcina, doña Elvira Ponce de Lcón. Esa familia libresca se corona en el prólogo con este hijo legítimo, más suyo que cuantos le prohijaran al autor. Su reducidísimo formato (lo califica de «átomo») viene, sin embargo, a contener en la estampa de la Eucaristía la mayor grandeza. La precisión de Gracián al describirlo Ilega a detallar el uso, "tan manual, que le pueda llevar cualquicra ó en el seno, ó en la manga» ${ }^{15}$.

Libro entre libros que anuncia además otro «de oro» sobrc la muerte de Cristo, y que presenta al final un «Índice de las Meditaciones» que es auténtico ejemplo de mnemotecnia visual, seguido de una tabla práctica para comulgar en todas las festividades del año. Nos encontramos así con una ordenada disposición tipográfica y textual ligada al calendario litúrgico. El opúsculo es un cjemplo más de aprovechamiento por parte de Gracián de las ventajas

13.- Gracián quiere diferenciar al hombre de palabras del de obras (p. 410) y dice que «las palabras son sombras de los hechos» (p. 419) y la lengua "pulso del alma» (p. 423). I'éngase en cuenta la relación establecida por Felice Gambin, "Conoscenza c prudenza in 13. Gracián», Filosofia politica I, 1987, pp. 257-283.

14.- Vide pp. $428-9$, 436 y 438.

15.- El Commlgatorio. Contiene varias meditaciones, para que los que frecuentan la sagrada Comumión, puedan prepararse, comulgar, y dar gracias. Por El P. Balrasar Gracián de la Compañía de lesís, Laragoza, Juan de Ybar, 165.5. Mancjo el cjemplar encuadernado de la Biblioteca Nacional 2/485, de die\%. por siete centímetros, por el que citaré. La camarera real es mera intermediaria para que el libro llegue a manos de la reina. El prólogo al lector se dirigirá, en cambio, a las almas devotas. Gracián ordena el contenido y justifica su estilo: "es el que pide el tiempo». Cada meditación se repante en cuatro puntos a lo largo de toda la obra. Cada punto desglosa el epígrafe que introduce todas las meditaciones. Para la mnemotecnia de esta obra, Fernando Rodrígue\% de la Flor, "El Commlgalorio de Baltasar Gracián y la tradición jesuítica de la compositio loci», Revista de Literatura 44, 1981, pp. 5-18. 


\section{AURORA EGIDO}

de la composición impresa. Dividiơa cada una de las meditaciones en puntos, éstos se caracterizan por su tono mostrativo y apclativo, invitanclo al lector a la oportuna composición de lugar. Su final, a nodo de oración, cierra la recreación mental con resoluciones morales. Lo más curioso es que, entre frases, los asteriscos invitan al descanso en la lectura. Claro que no es sólo el sentido de la vista el que se recrea, sino el del gusto en la comida espiritual.

Autor y lector se identifican en la primera persona de la compositio loci y en la de las imagines recreadas: "Imagíname subido en el árbol de la contemplacion». Uso que se extiende a la evidencia eucarística: "Yo soy lesus». y a otras instancias de este texto que apelan a los cinco sentidos y a la demostratio viva ${ }^{16}$. Fil libro todo, en su disposición y composición tipográfica, es un ejemplo de obra impresa, útil, breve y ordenada al servicio de la práctica religiosa. Manual cucarístico de uso común.

l.a Agudeza, libro de libros fragmentados y glosados al servicio del ingenio, remite a cllos ya desde la dedicatoria a lastanosal. Gracián dirige a su propia obra apelativos que la personifican en una línea que, una vez más, remite a Marcial. Lo misterioso y recóndito del nombre aparece desde los inicios ${ }^{1 \%}$. Sin embargo, esia aspiración conceptual, contra lo que pudiera parecer, no construye a lo largo de la obra un tejido de alusiones tipográticas superior al de los demás tratados de Gracián. El hecho no parece baladí y confirma, entre otras cosas, el territorio en el gue verdaderamente se mueve el concepto gracianesco.

Se juega con las palabras y su disposición, pero ésta no es necesariamente gráfica, aunque se implique, particularmente en las referencias a cmblemas y jeroglílicos que Ilenan la obra. El ingenio vuelve del revés las letras y las palabras ( Roma, Amor, dice leido...») "s. Éstas son ambivalentes, significan a una o más luces, encerrando un alma conceptuosa "'. Del libro a la página, a la frase y a la letra, Gracián recorre todos los espacios de la escritura, incluiclo el de la acentuación, pues «no es menester muclar sílabal, que una sola tilcle bastal para

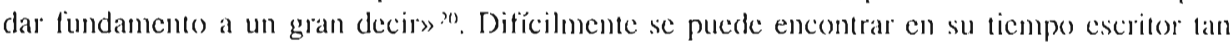
preocupado por las grafías y su significación. "Trocar alguna letra o sílaba de la palabra o nombre para sacarle al otra signilicación» - nos dirá es fundamento de agucleza ${ }^{21}$. Paronomasias, retruécamos y otros juegos muestran el triple artificio, verbal, gráfico y conceptual que la palabra implica. Esa «hidra bocal» graciana que hace de clla un ser vivo y mudable se extiende por toda la obra. Fel artificio de los laberintos y el dibujo de los anagramals conforman otros tantos casos de mutación, relación y capacidad asociatival del lenguaje. La gralía

16.- El presente («meditarás hoy») actualizal permanentemente el texto, así como los otros décticos y recuentos que van del pasado al aquí y ahora, como en el referido a la cantuca. "Pondera», "celebra». elc. son muestras concretas de actualización. Todo se hace presente, en una puesta en escena a lo vivo.

17.- Ballasal (jlacián, Agudeza y arte de ingenio), ed. de E. Correa Calderón. Matdrid, Castalia, 1969 I, p. 46. Fn ella se alude a que el rey mandó copiar el Arte de ingénio para su biblioteca (I. p). 4.3-4). R:jemplo claro de cómo las copias mamuscritas pervivicron en el Siglo de Oro, incluso de ejemplanes (pue yal andaban impresos. Gracián, auncue hace referencia a libros y matados (el (juzmán. por ejemplo, II, p. 12), liende a lat cila fragmentaria, como es obvio.

18.- Para Roma-amor, II. p. 42. Y véanse, para el juego Isabel-selbe (a) iel. I. p. 49; para "O. nix, flamma mean, I p. 55, etc. Ial referencia a jeroglílicos implica, con la de los emblemas. un escribir como pintar (I, pl). 181 y II, p.23).

19.- II, p. 49. Ciracián habla cle "muclal" y combinall sílabas. II. p. 46.

20.- Sólo gráficamente, por la equivalencia, en la ortografía de la época, de la tilde a la n, se puede explicar el juego del «Rui», equivalente a ruín, a que alude (iracián (II. p.5()).

21.- 11, p. 46. Son muchos los ejemplos basados en la mudanzal y combinación de sílabas, como se sabe, en la obra. Véase el de un epigrama «leido al revés», II, p. 165. 


\section{LA FSCRITURA FN LOS 'TRATAIDOS DE BALITASAR GRACIÁN}

se pone así al servicio del concepto y de la inteligencia para enricuecerlos². Fil lector, por su parte, debe operar activamente y desentrañar el misterio del signilicado que se le ofrece. la Agudeza demuestra que los conceptos implican palabras dichas, pero también escritas, siendo éstas en algunas ocatsiones las (jue soportan en sus grafismos la verdadera esencia conceptual.

Citas y libros leídos y releídos sobre los que se puede volver, ya que están eternizados por la escritura, invaden el texto. Acpuélla los fijja para ser susceptible de lecturas interminables, como es el casso de l:l Comde lacemor, "siempre agradable, auncuic sicte veces se lea ${ }^{23}$. I a facultad de cercenar los textos, aclaptarles, mudarlos y darles nuevo senticlo es inacabable, como la de las palabras mismas. Ciracián se sitúa, en este sentido, muy cercal de Góngora o de Marino en el arte de trasladar, copiar, robar, recrear. Descifiar palabras como alusiones es tarea (lel ingenio. Cifrar y descifrar son operaciones permanentes de la escritura y de la lectura ${ }^{24}$. De "sutileza en cifia» califica una cita cle Marcial y orals prolundidades del concepto's.

Cuantitativamente priman, como se dijo, los planteamientos verbales o conceptuales alsstractos, pero Giacián no obvia, sino que explicila, la operación de leer, hasta en la vuelta de hoja, al hilo de una referencia a Horacio ${ }^{2 t}$. Oír como leer se entiende de forma sincrónica, pero en una operación que no acaloa en sí misma, sino que remite a un proceso dé entendimicnto?

Mundo de cilals el de la Agudeza, pero también de dichos, apelando a autoridades cue son letra manuscrita o impresa, parte de una crudición que se clogia con ardor y que resicle en las encomiadas bibliotecas ${ }^{3 .}$ I a agude $\%$ y arte de ingenio verbal tiene desde luego su permanente correlato gráfico y tipográfico. (Grafia, por otro lado, que es cifra, según se ha dicho, y que siempre remite a sus autores. Acto de escritura que puede ser, entre juego y alma de quien lo ejecula, «sudor» del espíritu 2".

Fil concepto reside en una tikde o en un epítero, pero la grafía siempre implica una voz, alta o silenciosa, sin la que su pictura carecería de sentido". I a tradición oral clel conceptismo suele estar presente en toda la obia, con su doble actuar de voces y letras.

22.- Véase, al respecto, el discurso XXXII, II pp. 50 s.s. Y olro tanto ocurre en el dedicato a los equívocos ingeniosos. 11, p. 5.5 .

23.- 11, pp. 77-8. Los equivocos por acomoclación ke verso antiguo, texto o autoridad, en II, pl). 62 ss.

24. - 1. p. 95 y II. p. 1.52.

25.- II, p. 1.52 y véase II, p|). 155.156 y 1.59.

26.- II. p. 127

27.- Véase II, p. 169: lan pesado es, para el que lee como para el que oye durante una horia, la enfidosal cáreel de la metáfolia. (iracián cree que la eminencia no reside en los aspectes matteriales cuantitativos y cualitativon de las sílabas y de su cadencia, pues tan sólo alpelan al ódo. "En la elegancia del decir, en el antificio def discurrir, en la prolundiclad del declarar» (II, p. 198) está la esencia de la agudeza.

28.- Véasc el elogio de la erudición en II. p. 218 . Respecto a las librerías o bibliotecas, los consabidos elogios a la de lastanosia (I. p. 143). Escalígere o Juan de (iariz (1. p. 216 y 237, respectivamente). la invilación a leer y a las bibliotecas es permamente (II. p. 8).

29.- "Escribió Comelio Tácito, no con tinti, sino con el sudor de su vallicnte espíritu» (II, p. 228). In lit Criticón menucleará en referencias a la tintal-sangre-sudor.

30.- Véalse II, p. 201, para el juego Jo-Yo. Fonema y gralema no tienen por qué ser coincidentes. Gracián distingue los dos planos de la lengna, hablada y escrita, auncue es consciente de su identilicación y paralelismo. Sobre el tema, E. Pulgram, «Phoneme and Crapheme: a Parallel», Word, 7, 1951, pp. 1520: (i. Hammarström, "Graphème, son el phonème dans la description de vieux textes». Sundia Ne(ophi- 
Gracián ofrece una amplia gama de referencias cxplícitas a la escritura y, a la par, una permanente reflexión sobre ella, hasta constituir toda una teoría y práctica del signo. Si la presencia de la oralidad es constante y late en la grafía, ésta se declara como un universo que no sólo contiene a aquélla, sino que se afirma en su espacialidad y progresión temporal. Los signos de la escritura sobre el blanco de la página, manuscrita o impresa, alcanzan significados concretos hasta formar una retórica y una poética de la grafía, no exentas de apreciaciones éticas. El jesuita, consciente de las posibilidades de todo tipo que la imprenta ofrecía, escribió sus tratados con una obvia proyección tipográfica, de uso manual ${ }^{31}$. Desde los signos demarcativos a la disposición de los pliegos y la composición, pasando por secuencias menores, como letras, palabras, espacios marginales, etc., Gracián sc adelanta a los teorizadores modernos que, como L. Rosiello, distinguen dos planos en el texto: uno dependiente del sistema fónico y otro autónomo, con significado y función propios ${ }^{32}$.

La fusión de significante y significado, así como la doble percepción, oral y visual, de la escritura, se deducen claramente de unos tratados medidos hasta en los más mínimos detalles de la impresión. Su cercanía al grupo de Andrés de Uztarroz, heredero de Antonio Aguslín, le permitió acceder a los conocimientos que la epigrafía de su tiempo le ofrecía. La escritura como dibujo que se desarrolla espacialmente, fijando el lenguaje y preservándolo del olvido, está latiendo en cstos tratados del jesuita, particularmente en la Agudeza, auténtico arte de la memoria ingeniosa ${ }^{33}$. En ella, Gracián teoriza y practica, como en el resto de su obra, con toda sucrte de grafías dedálicas, mostrando la importancia conceptual que tenían los emblemas, epigramas, enigmas, adivinanzas, acrósticos, anagramas y laberintos. El artificio gráfico era algo más que conformación y fijación visual, alcanzando otros niveles de significación y aún de simbolismo. Él cra consciente de que, a fin de cuentas, para poder alcanzar el alma del significado y la voz de sus autores, sólo tenemos la grafía o la tipografía a través de las cuales éstos han sobrevivido. Los dicta et facta permanecen a través de los escritos que los conservan, aunque la transmisión oral sea, desde luego, fundamental.

La humanización del acto de la escritura, la idea compartida con Marcial del libro-niño y, a la ve\%, hijo de su autor, están presentes en la retórica prologal y en otras partes de los tratados, colaborando en el establecimiento de su función ética. Gracián se preocupa del acto de escribir y del de leer, de los mecanismos simbólicos de la pluma, así como de los blancos de la página sobre los que aquélla se extiende. Estilo y formato van íntimamente ligados. El laconismo conceptuoso y la brevedad de sus manuales son consecuentes con la prédica de una erudición y agudeza concentradas, en cifra que requiere del lector esfuerzo y trabajo del entendimiento. La microcosmía alcanza al hombre y al libro. Vida y obra, como hemos dicho de El Discreto, discurren a la par. Leer, escribir y vivir son uno y lo mismo. El libro es ali-

lologica 31, 1959, pp. 5-18 y A. Avram, «Sur quelques particularités des systèmes graphematiques», $C a-$ hiers de linguistique théorique et apliquée, 1, 1962, pp. 1-16.

31.- Sobre las «Ncografías» o formas gráficas posteriores a la invención de la imprenta, Elisa Ruiz, Mamual de Codicología, Madrid, Fundación G. Sánchez. Ruipére\%, 1988.

32.- L. Rosiello, "Grafematica, fonematica e critica textuale», Lingua e stile, I, 1966, pp. 63-77. Y véasc, como contraste, E. Scoles, "Criteri ortographici nelle aedizioni critiche di testi castigliani e teorie grafematiche», Studi di Letleratura Spagnola, 3, 1966, pp. 1-16. La discusión es fundamental, como se sabe cn la crítica textual.

33.- Sobre cllo y para un estado de la cuestión sobre las teorías referentes al lenguaje oral y escrito, el capítulo VIII de Elisa Ruiz, Ilacia una semiología de la escrimura, Madrid, Fundación Sánchez. Ruipére\%, 1992, pp. 218 ss. Para la escritura como arte mnemotécnico, el clásico libro de Jack Seady, l.a domesticación del pensamienso salvaje, Madrid, Akal, 1985. 


\section{LA ESCRITURA EN LOS TRATADOS DE BALTASAR GRACIÁN}

mento y vida, conversación y modelo, confidente y amigo. Todo texto se genera a partir de otros textos que lo conforman, contituyéndose en memoria propia y ajena.

De cómo la escritura se pone al servicio de lo trascendente da señales El Comulgatorio. libro medido no sólo en la composición de lugar de sus meditaciones, sino en la del texto que las contiene. La Agudeza se abre a consideraciones de otra índole, ceñida a cuanto la grafía supone para el artificio conceptual. Ejemplo éste de hasta qué punto pensamiento, voz y escritura pueden andar unidos, contra ciertos presupuestos de Derrida ${ }^{34}$.

Gracián privilegió la voz como la letra, sirviéndose de ambas como vehículo y soporte conceptuales, pero vio también la incidencia que en el plano del ingenio tenían ambas. No creyó que la letra fuese simplemente representación de la voz, sino portadora de su propia significación y función. Y ello tanto en el plano estético como en el filosófico y moral. Él no sólo se adelantó a algunos de los principios de la gramatología moderna, incluidos los elementos marginales, sino que percibió en la escritura lineal la sucesión irreversible del tiempo, como ocurre en el curso y el discurso de El Criticón.

Pero más allá de toda trascendencia, Gracián tuvo un alto sentido práctico en sus tratados, aunque la Agudeza merecería consideración aparte. El Héroe, El Político, El Discreto, el Oráculo y El Comulgatorio son libros mínimos, manuales, hechos para llevarlos cabe uno y lecrlos en cualquier momento y lugar. Su estilo es consustancial a su formato. Marcial parece ser el modelo del jesuita, no sólo porque hable constantemente en sus Epigramas de las excelencias de lo breve y limado, sino porque ensalza precisamente los manuales que sirven para ser llevados de un sitio a otro ${ }^{35}$. Marcial habla de las ventajas del libro sucinto, con palabras no exentas de humor:

En primer lugar, gasta menos papel; segundo, el copista lo termina en el espacio de una hora y no tendrá que ocuparse únicamente en mil bagatelas; tercero, que si por casualidad eres leído a alguien, aunque seas malo desde el principio al fin, no le resultarás odioso ${ }^{36}$.

34.- Cristina de Peretti, Jacques Derrida: Texto y deconstrucción, Barcelona, Anthropos, 1989, pp. 31 ss. Derrida distingue entre logocentrismo (pensamiento) y fonocentrismo (voz) como relación que sc opone a escritura y que va en su detrimento. Según él, ya desde Grecia, con el Fedro de Platón, se impone un discurso logofonocéntrico que condena la escritura a mero soporte del significado.

35. Epigramas de Marco Valerio Marcial, ed. de José Guillén, Zaragoza, Institución Fernando el Católico, 1986, p. 60. Incluso llega a decir que se le acusaba por su ahínco en escribir libros pequeños (p. 73). 36.- Ib., p. 99. El diminutivo «librito» aparece varias veces (pp. 288-9 y 317, entre otros). En el libro X, dice: «Si te parczco un libro demasiado grueso y demasiado largo, y al que nunca sc le ve el fin, lec sólo algunos epigramas y seré librito. Tres o cuatro veces termino la página con un epigrama corto, ha\%me tú lo breve que descas» (p. 367). Henry-Jean Martin ha llamado la atención sobre la «ventilación" de la página en los siglos XVI y XVII, proclives a los blancos y a la fragmentación de textos en unidades pequeñas. Vide Bruno Delmas, Historic el Poltvoirs de l'Écrit, París, Librairie Académique Perrin, 1988, pp. 295-9. La rclación entre imprenta y significado, en D. F. Mckenzic, «Typography and Mcaning: the Case of William Congreve», Buch und Buchandel in Europa im achtzehnten Jahrhundert, Hamburg, E. Hauswedell, 1981, pp. 81-126. Para la huella de Marcial en la litcratura española y en Gracián, véase la tesis doctoral de Anthony A. Giulian, Martial and the Epigram in Spain in the Sixteenth and Seventeenth Centuries, Philadelphia, 1930, pp. 79 ss. El autor no hace referencia al tema que nos ocupa. La defensa del libro pequeño entró en el humanismo de la mano de Petrarca, según ha indicado Armando Petrucci, Libri, scritture e pubblico nel Rinascimento. Guida storica e critica, Roma, Laterza, 1979, p. 11. Esa defensa y la de la letra romana supuso una reacción contra el libro escolástico, de gran formato y letra gótica. El libro pequeño cra símbolo de renovación humanística. Otros aspectos y bibliografía so- 


\section{AURORA F.(IIDO}

F. libro, descle el momento mismo de la escritura hasta el de la lectura, se vincula, en Marcial como en el jesuita, a la mano que lo escribe y que lo contiene en el acto de leerlo. Fn él cabe el mundo abreviado de los héroes, discrelos y prudentes, pero lambién los misterios sagrados, como es el caso de Fl Comulgettorio, la más pequeña de sus obras y, sin embargo, la que pone al servicio de una causa más alta.

Cuando en El Criticón construya una ambiciosa alegoría de la escritura no hará sino desarrollar los presupuestos de su obra anterior para convertirlos en parte fundamental del discurso.

bre el tema, en mi trabajo en prensa, "I,a letra en El Criticón», ponencia leída en el XI Congreso de la Asociación Internacional de Hispamistas (Universidad de lrvine. 24-9) de agosto de 1992) de próxima aparición en el Bullerin Ilispamique. 